\title{
The Escherichia coli small heat-shock proteins IbpA and IbpB prevent the aggregation of endogenous proteins denatured in vivo during extreme heat shock
}

\author{
Dorota Kuczyńska-Wiśnik, ${ }^{1}$ Sabina Kȩdzierska, ${ }^{1}$ Ewelina Matuszewska, \\ Peter Lund, ${ }^{2}$ Alina Taylor, ${ }^{3}$ Barbara Lipińska ${ }^{1}$ and Ewa Laskowska ${ }^{1}$
}

Author for correspondence: Ewa Laskowska. Tel: +4858 30157 41. Fax: +48 583010072. e-mail: lasko@biotech.univ.gda.pl

1 Department of Biochemistry, University of Gdańsk, Kładki 24, 80-822 Gdańsk, Poland

2 School of Biosciences, University of Birmingham, Birmingham B15 2TT, UK

3 Department of Molecular Biology, University of Gdańsk, Kładki 24, 80-822 Gdańsk, Poland

\begin{abstract}
The roles of the Escherichia coli IbpA and IbpB chaperones in protection of heat-denatured proteins against irreversible aggregation in vivo were investigated. Overproduction of IbpA and IbpB resulted in stabilization of the denatured and reversibly aggregated proteins (the $S$ fraction), which could be isolated from $E$. coli cells by sucrose gradient centrifugation. This finding is in agreement with the present model of the small heat-shock proteins' function, based mainly on in vitro studies. Deletion of the ibpAB operon resulted in almost twofold increase in protein aggregation and in inactivation of an enzyme (fructose-1,6-biphosphate aldolase) in cells incubated at $50^{\circ} \mathrm{C}$ for $4 \mathrm{~h}$, decreased efficiency of the removal of protein aggregates formed during prolonged incubation at $50{ }^{\circ} \mathrm{C}$ and affected cell viability at this temperature. IbpA/B proteins were not needed for removal of protein aggregates or for the enzyme protection/renaturation in cells heat shocked at $50^{\circ} \mathrm{C}$ for $15 \mathrm{~min}$. These results show that the IbpA/B proteins are required upon an extreme, long-term heat shock. Overproduction of IbpA but not IbpB caused an increase of the level of $\beta$-lactamase precursor, which was localized in the $S$ fraction, together with the IbpA protein, which suggests that the unfolded precursor binds to IbpA but not to IbpB. Although in the wild-type cells both $E$. coli small heatshock proteins are known to localize in the $S$ fraction, only $2 \%$ of total IbpB co-localized with the aggregated proteins in the absence of IbpA, while in the absence of IbpB, the majority of IbpA was present in the aggregates fraction.
\end{abstract}

Keywords : protein aggregation, $\beta$-lactamase precursor, DnaK

\section{INTRODUCTION}

Small heat-shock proteins (sHsps) are one of the families of molecular chaperones preventing the irreversible aggregation and assisting in the refolding of denatured proteins. The sHsps have been found in all organisms tested so far and are characterized by their low molecular mass $(12-30 \mathrm{kDa})$, oligomeric structure and the presence of a conserved ' $\alpha$-crystallin' domain (Jacob \& Buchner, 1994). The sequence of this domain is highly similar to the vertebrate protein $\alpha$-crystallin which prevents the formation of cataracts associated with protein aggre-

Abbreviations: $C P$, cytoplasmic and periplasmic; IM, inner membrane; OM, outer membrane; sHsps, small heat-shock proteins. gation in the eye lens (MacRea, 2000). According to the present model, ATP-independent sHsps bind and stabilize denatured proteins in a folding competent state, preventing their irreversible aggregation. The stabilized proteins are subsequently delivered to the Hsp70-Hsp40 chaperone system for ATP-dependent refolding (Ehrnsperger et al., 1997; Veinger et al., 1998; Lee \& Vierling, 2000). Escherichia coli has two members of the sHsps family, IbpA and IbpB proteins, sharing $50 \%$ amino acid homology and identified for the first time as proteins bound to heterologous proteins forming inclusion bodies in E. coli cells (Allen et al., 1992). We have previously found that $\mathrm{IbpA}$ and $\mathrm{IbpB}$ are major components of the $S$ fraction which contains endogenous, heat-denatured E. coli proteins, separated from the 
membranes and soluble proteins by sucrose gradient ultracentrifugation (Kucharczyk et al., 1991; Laskowska et al., 1996a). The $S$ fraction appears in E. coli wild-type (WT) cells $15 \mathrm{~min}$ after the temperature change from $30{ }^{\circ} \mathrm{C}$ to $45^{\circ} \mathrm{C}$. During subsequent growth at $37^{\circ} \mathrm{C}$, the $\mathrm{S}$ fraction disappears due to refolding and degradation of the aggregates by heat-shock proteins. Removal of the $S$ fraction is inhibited or retarded by mutations affecting the heat-shock proteases and chaperones Lon, HtrA, ClpP, ClpX, ClpA, ClpB, DnaK, DnaJ and GroEL/ES (Laskowska et al., 1996b; Kędzierska et al., 1999). The $\mathrm{S}$ fraction is also stable in $r p o H$ cells, which lack active $\sigma^{32}$, the transcriptional activator of heat-shock genes (Kucharczyk et al., 1991).

To date, IbpB protein is the only E. coli sHsp examined for its chaperone activity in vitro, whereas IbpA has not been tested, as it tends to aggregate during all stages of purification (Shearstone \& Baneyx, 1998). It was found that $\mathrm{IbpB}$ reduced thermal aggregation of model substrates: citrate synthase and alcohol dehydrogenase (Shearstone \& Baneyx, 1998) and formed a stable and soluble complex with MDH which was refolded subsequently by the DnaK/DnaJ and GroEL/GroES systems (Veinger et al., 1998). Compared to the considerable amount of data derived from studies on the in vitro systems, there is not much information available on the in vivo function of the IbpA/B proteins. Kitagawa et al. (2000) found that E. coli strains overproducing IbpA or $\mathrm{IbpB}$ acquired higher levels of resistance to heat and oxidative stresses and accumulated lower amounts of aggregated proteins after exposure to $50{ }^{\circ} \mathrm{C}$ than the WT strain. Deletion of the $i b p A / B$ operon affected neither the cell viability nor the intracellular protein aggregation at high temperature. The only phenotypic change observed in a $\Delta i b p A / B$ mutant was a slightly slower growth at $46{ }^{\circ} \mathrm{C}$ (Thomas \& Baneyx, 1998).

It was demonstrated that $\mathrm{IbpB}$ assembles in vitro into oligomeric structures of heterogeneous size. The basic $600 \mathrm{kDa}$ oligomers are roughly spherical and interact to form larger complexes (Shearstone \& Baneyx, 1998). There is no evidence that IbpA and IbpB are assembled into mixed complexes in E. coli cells, although in organisms containing more than one sHsp, different sHsp species form hetero-oligomers, for example: vertebrate $\alpha \mathrm{A}-\alpha \mathrm{B}$-crystallin, $\alpha \mathrm{B}$-crystallin-Hsp27 and sHsps from Bradyrhizobium japonicum $(\mathrm{HspH} / \mathrm{HspB}$ and HspC/HspF) (MacRea, 2000; Liu \& Welsh, 1999; Studer \& Narberhaus, 2000). IbpB was also found to form mixed oligomers with $\mathrm{HspB}$ and $\mathrm{HspH}$ of $B$. japonicum (Studer \& Narberhaus, 2000). It is not clear either whether IbpA and IbpB are functionally equivalent. The fact that overproduced IbpA in $\Delta i b p A / B$ cells was partitioned between soluble and insoluble cellular fractions whereas overproduced $\mathrm{IbpB}$ was located mostly as a soluble protein (Shearstone \& Baneyx, 1998) suggests that E. coli sHsp may have a different affinity for unfolded proteins. The studies on sHsps of $B$. japonicum revealed that the chaperone activity of purified hetero-oligomers is indistinguishable from the activity of homo-oligomers. On the other hand, it was reported that vertebrate $\alpha$-crystallin homooligomeric complex containing $\alpha \mathrm{A}$ - or $\alpha \mathrm{B}$-subunits differs in lens plasma-membrane-binding properties from heteromeric $\alpha$-crystallin (Cobb \& Petrash, 2000). Furthermore, $\alpha \mathrm{B}$-crystallin is a more efficient chaperone in preventing aggregation of the heat-inactivated citrate synthase than $\alpha \mathrm{A}$-crystallin (Rajaraman et al., 2001).

The purpose of this work was to investigate further the role of IbpA and IbpB in the protection of heatdenatured proteins against irreversible aggregation in vivo. It was found previously that excess of DnaK/DnaJ or GroEL/GroES chaperones prevented the formation of the $S$ fraction during heat shock (Kędzierska et al., 1999). In this work we examined whether overproduction of IbpA and/or IbpB proteins resulted in the opposite effect, stabilization of the $S$ fraction, as should be expected from the current model of the sHsps function. Finally, we have characterized the effect of deletion of the $i b p$ operon on the protein aggregation in E. coli cells upon extreme heat shock at $50{ }^{\circ} \mathrm{C}$.

\section{METHODS}

Bacterial strains, plasmids and culture conditions. MC4100 [araD139 $\Delta$ (lacIPOZYA $\operatorname{argF}) U 169$ fla relA $r p s L]$ was used as a WT strain. In MC4100 $\triangle i b p A / B$, the majority of the $i b p A B$ operon (892 bp BstXI region) is replaced by the BsaAI-BclII fragment containing the $\mathrm{cm}$ gene from pACYC184. pCA, pCB and $\mathrm{pCAB}$ plasmids are pUC derivatives bearing $i b p A, i b p B$ and $i b p A B$ genes, respectively, under control of the pTac promoter. The XL-1 Blue strain with pKEN8 plasmid overproducing the E. coli fructose-1,6-bisphosphate aldolase was purchased from the American Type Culture Collection (ATCC 77472). For the $\mathrm{S}$ fraction isolation, cultures were grown to exponential phase at $30^{\circ} \mathrm{C}$ or $37^{\circ} \mathrm{C}$ in $100 \mathrm{ml} \mathrm{LB}$ medium supplemented with $100 \mu \mathrm{g}$ ampicillin $\mathrm{ml}^{-1}$, if required, and shifted to $45^{\circ} \mathrm{C}$ or $50^{\circ} \mathrm{C}$.

Cell fractionation and isolation of the $\mathbf{S}$ fraction. This was done essentially as described by Kucharczyk et al. (1991). Briefly, cells were harvested, converted into spheroplasts, lysed by sonication and fractionated by ultracentrifugation in a two-step SG0 sucrose density gradient to separate insoluble material [aggregated proteins ( $\mathrm{S}$ fraction), and outer (OM) and inner (IM) membranes] from soluble, cytoplasmic and periplasmic proteins. Then the insoluble fraction was loaded on a six-step SG1 gradient to separate the $S$ fraction containing aggregated proteins from the OM and IM. Thirty subfractions were collected from the bottom of a tube and analysed for protein concentration according to the method of Bradford (1976).

Analytical methods. Proteins were resolved by SDS-PAGE according to Laemmli (1970). To estimate the contribution of overproduced IbpA and IbpB to the S fraction, the aggregated proteins were resolved by SDS-PAGE and Coomassie bluestained gels were analysed by scanning densitometry (Sigma Gel). Two-dimensional PAGE was performed as described by Laskowska et al. (1996b), using $1.6 \%$ pH 6-8 and $0.4 \%$ pH 3.5-10 carrier ampholite mixture (Pharmacia). Polyclonal rabbit antisera against $\mathrm{IbpA} / \mathrm{B}$, DnaK and Fda, anti-rabbit peroxidase conjugate (Sigma) and substrates 4-chloro-1naphthol and $\mathrm{H}_{2} \mathrm{O}_{2}$ (Serva) were used for protein immunodetection. Membranes were scanned and analysed with the Sigma Gel program. For microsequencing, proteins were 
subjected to $0 \cdot 1 \%$ SDS-12\% PAGE and electrotransferred to PVDF (Serva) according to the method of Wilson \& Yuan (1989). The N-terminal amino acid sequence analysis was performed on a gas-phase sequencer (model 491, Perkin Elmer Applied Biosystems) at Biocenter (Jagiellonian University, Krakow, Poland). For the Fda activity determination in cell extracts, a coupled-enzyme assay for the fructose 1,6-bisphosphate was carried out according to the Sigma protocol as described by Kędzierska et al. (2001), except that the cultures were grown in LB medium. The activity of $\beta$-lactamase was determined using penicillin $G$ as a substrate (Meerman \& Georgiou, 1994) in cell lysates prepared for the $S$ fraction isolation.

\section{RESULTS}

\section{Overproduction of IbpA and IbpB stabilizes aggregates of denatured proteins in vivo}

To distinguish the role of IbpA and IbpB in the $S$ fraction formation and removal, we used the MC4100 $\Delta i b p A / B$ mutant strain transformed with pUC18 derivatives: $\mathrm{pCA}, \mathrm{pCB}$, or $\mathrm{pCAB}$ plasmids bearing $i b p A, i b p B$ and $i b p A B$ genes, respectively. Since MC4100 is $\Delta l a c$, IbpA and/or IbpB proteins were produced without the addition of IPTG at a constant level, approximately eightfold higher than that in the WT cells heat shocked at $45{ }^{\circ} \mathrm{C}$ for $15 \mathrm{~min}$. For the $\mathrm{S}$ fraction isolation, culture samples were taken at time 0 , i.e. just before the temperature shift to $45^{\circ} \mathrm{C}$, after $15 \mathrm{~min}$ at $45^{\circ} \mathrm{C}$, and during growth at $37^{\circ} \mathrm{C}$ at the 25 th min, 35 th min and 45 th min of the experiment. SDS-PAGE analysis of the aggregated proteins showed that IbpA and IbpB were the most abundant proteins in the $S$ fraction (Fig. 1a); however, the amount of IbpB was lower than that of IbpA. Overproduction of both IbpA and IbpB and their localization in the $S$ fraction of the strain transformed with $\mathrm{pCAB}$ was confirmed by two-dimensional PAGE (not shown). To compare the levels of aggregation in the control and the IbpA/B overproducing strains (Fig. 1b), the amount of aggregated proteins was calculated in relation to the total protein $(100 \%)$ after subtraction of the IbpA/B level (see Methods). In the control strain MC4100 $\Delta i b p A / B(p U C 18)$, at the 15th min after heat shock, $2 \%$ of total cellular proteins were aggregated and formed the $\mathrm{S}$ fraction, which disappeared in the next

(a)

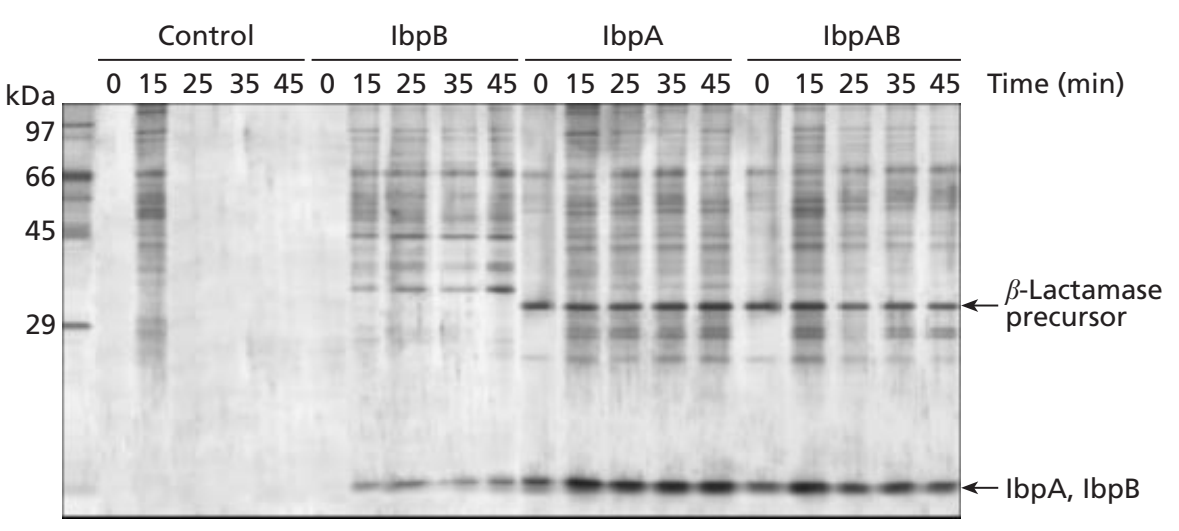

(b)

Control

$\mathrm{IbpB}$

IbpA

$\operatorname{IbpAB}$
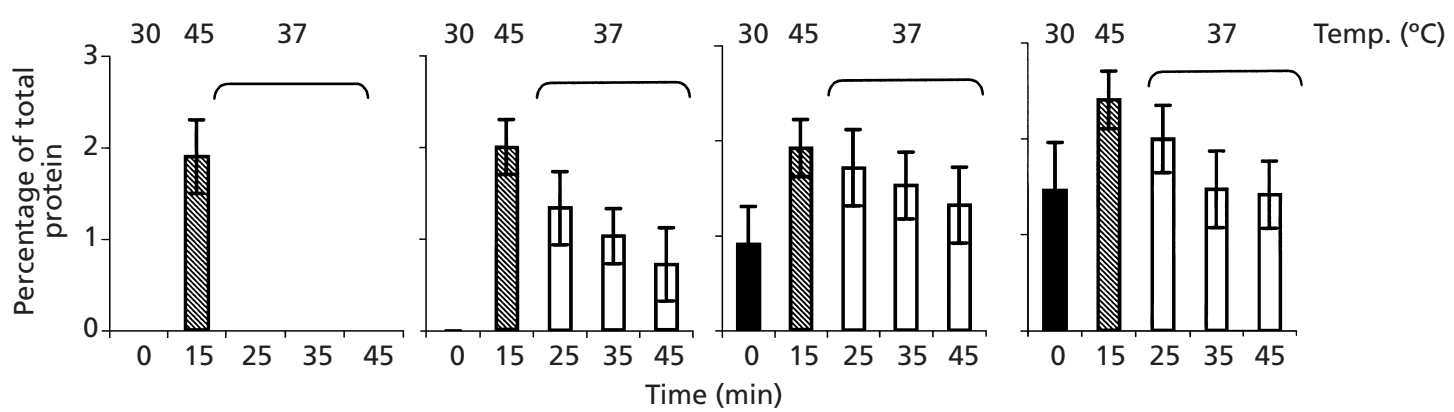

Fig. 1. The rise and removal of the $S$ fraction in $E$. coli cells overproducing $\mathrm{lbpA}$ and $\mathrm{lbpB}$ proteins. E. coli MC4100$\Delta i b p A / B(\mathrm{pUC18})$ control strain, MC4100 $\Delta i b p A / B(\mathrm{pCAB}), \mathrm{MC4100} \Delta i b p A /(\mathrm{pCA})$ and $\mathrm{MC4} 100 \Delta i b p A / B(\mathrm{pCB})$ were grown at $30^{\circ} \mathrm{C}$ in LB medium. At an $\mathrm{OD}_{595}$ of 0.3 the bacteria were submitted to heat shock $\left(15 \mathrm{~min}, 45^{\circ} \mathrm{C}\right)$ and then transferred to $37^{\circ} \mathrm{C}$. The $\mathrm{S}$ fraction was isolated from samples taken at time 0 (before the temperature shift), after $15 \mathrm{~min}$ at $45^{\circ} \mathrm{C}$ and at the 25th, 35th and 45th min during incubation at $37^{\circ} \mathrm{C}$, as described in Methods. (a) SDS-PAGE analysis of the S fraction isolated from MC4100 $\Delta i b p A / B$ overproducing IbpA and/or IbpB. Samples $(20 \mu \mathrm{l})$ of the $S$ fraction were subjected to $0.1 \%$ SDS- $15 \%$ PAGE followed by silver staining. The positions of IbpA/B and pre- $\beta$-lactamase are shown by arrows. (b) The amount of aggregated proteins (the $S$ fraction) was calculated in relation to the total protein (100\%) after subtraction of the IbpA/B level. Error bars represent the standard deviation of four values. 
10 min of incubation at $37^{\circ} \mathrm{C}$ (Fig. 1b). The same result was observed in the WT strain transformed with pUC18 (results not shown). In the mutant strain overproducing $\mathrm{IbpB}$, the amount of aggregated proteins was similar to that in the control ( $2 \%$ of total protein); however, removal of the $S$ fraction was delayed: at the 45 th min of the experiment, almost one-third of the aggregated proteins remained in cells. The overproduction of IbpA in the mutant strain had a more pronounced effect: the aggregates were formed even at $30{ }^{\circ} \mathrm{C}(0 \cdot 9 \%$ of total proteins). After the temperature shift (15th min), the $\mathrm{S}$ fraction reached $1.9 \%$ and after transfer to $37^{\circ} \mathrm{C}$ decreased to $1.3 \%$ of total proteins at the 45 th $\mathrm{min}$. When both E. coli sHsps were overproduced, larger amounts of proteins were aggregated: $2.4 \%$ and $1.4 \%$ of total cellular proteins were insoluble at the 15 th and 45th min, respectively, suggesting that IbpA and IbpB may act synergistically in the stabilization of the $S$ fraction. Interestingly, the growth of IbpA/B-overproducing strains was not affected by the stabilized aggregates (results not shown).

\section{The $\beta$-lactamase precursor aggregates with IbpA but not IbpB}

We analysed the protein content of the $S$ fraction of the $\triangle i b p A / B$ cells overproducing IbpA and/or IbpB proteins (Fig. 1a). The main difference in the protein content of the $S$ fraction aggregates was the presence of a $32 \mathrm{kDa}$ protein visible on the gel as a dominant component of the $S$ fraction isolated from cells overproducing either IbpA or both IbpA and IbpB. Aggregates containing IbpB (Fig. 1a) were not abundant in the $32 \mathrm{kDa}$ protein and were poorly separated from the OM fraction in the SG1 gradient, since the OM proteins OmpA and OmpF could be detected in the $S$ fraction (identified by Western blotting; not shown). The $32 \mathrm{kDa}$ protein, which aggregates in the presence of $\mathrm{IbpA}$ at $30^{\circ} \mathrm{C}$ as well as at $45^{\circ} \mathrm{C}$, was identified by $\mathrm{N}$-terminal sequencing and appeared to be a precursor of periplasmic $\beta$-lactamase coded by the bla gene carried by the IbpA/B-overproducing plasmids. We found that cells overexpressing IbpA or IbpA/IbpB also overproduced pre- $\beta$-lactamase, whilst the cells carrying only the pUC vector or overexpressing IbpB did not (Fig. 2). However, the activity of $\beta$-lactamase was comparable in all strains (results not shown). The observed overproduction of the $\beta$-lactamase precursor could be explained as follows. We assume that the unfolded precursor may be stably bound by IbpA but not by IbpB and, in consequence, in cells with high levels of IbpA (or IbpA/B) large amounts of the precursor would be trapped and not processed. This situation, in the presence of antibiotic $\left(100 \mu \mathrm{g} \mathrm{ml}^{-1}\right)$ would lead to increased production of the precursor which, after saturating available IbpA molecules, could be transported to the periplasm for processing. In conclusion, our results suggest that unfolded proteins (represented here by the $\beta$-lactamase precursor) may be bound stably by IbpA but not IbpB. This conclusion is supported by the results of experiments showing cellular localization of the IbpA/B proteins.

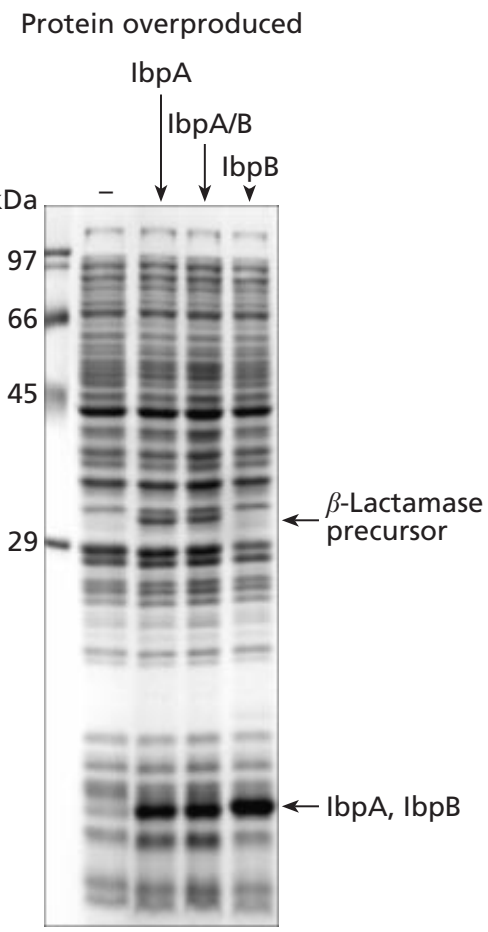

Fig. 2. The overproduction of IbpA results in increased levels of pre- $\beta$-lactamase. MC4100 $\triangle i b p A / B$ bacteria transformed with plasmids pUC, $\mathrm{pCA}, \mathrm{pCB}$ or $\mathrm{pCAB}$ were grown to exponential phase at $30^{\circ} \mathrm{C}$ in LB medium. Samples of cell extracts corresponding to the same amount of bacteria were prepared and analysed by $0.1 \%$ SDS- $15 \%$ PAGE. The gel was stained with Coomassie brilliant blue. The $\beta$-lactamase precursor is indicated by an arrow.

The immunodetection of the Ibp proteins in cellular fractions isolated from the $\triangle i b p A / B$ mutant overproducing IbpA or IbpB revealed that most of the IbpA co-localized with the insoluble, aggregated proteins of the $\mathrm{S}$ fraction, both at $30^{\circ} \mathrm{C}$ and after heat shock, whereas the vast majority of $\mathrm{IbpB}$ was found in a soluble cytoplasmic and periplasmic $(\mathrm{CP})$ protein fraction (Fig. 3 ). Approximately only $2 \%$ of total IbpB was present in the $\mathrm{S}$ fraction after heat shock. IbpA protein was also detected in the OM and IM fractions. We suppose that some IbpA molecules bind to the membranes after cell lysis, which would be consistent with the fact that IbpA, a cytoplasmic protein, is found mainly in the OM, not in the IM. When IbpA and IbpB were overproduced simultaneously, either at 30 or at $45^{\circ} \mathrm{C}$, both were present predominantly in the $S$ fraction and $\mathrm{IbpB}$ disappeared from the $\mathrm{CP}$ fraction (some IbpA/B was found in the $\mathrm{OM}$ fraction, probably as an artefact). In the last experiment, the presence of both Ibp proteins in the $\mathrm{S}$ fraction was confirmed by two-dimensional electrophoresis and immunoblotting (results not shown). These results support an idea that IbpA by itself, but not IbpB, may bind to unfolded (and aggregated) proteins and also show that IbpB localization changes in the presence of IpbA. The latter could be explained by the formation of IbpA-IbpB complexes, 

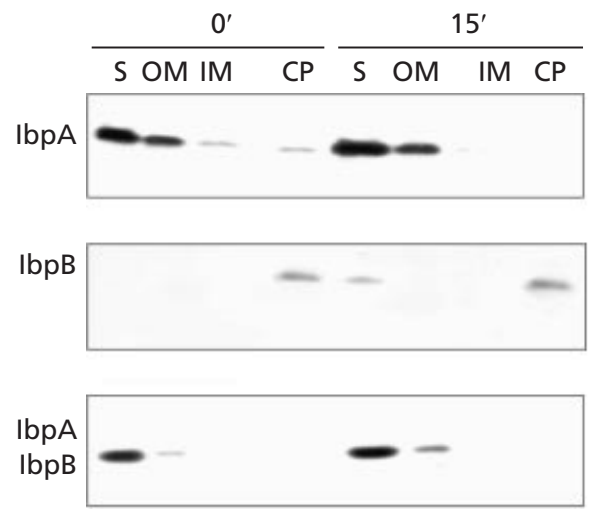

Fig. 3. Localization of $\mathrm{IbpA}$ and $\mathrm{IbpB}$ in cellular fractions of $E$. coli. The fraction of aggregated proteins (S fraction), outer membrane (OM), inner membrane (IM) and soluble, cytoplasmic and periplasmic proteins (CP) were isolated by sucrose density gradient ultracentrifugation from MC4100 $\triangle i b p A / B$ transformed with pCA (ibpA), pCB (ibpB) or pCAB plasmid (ibpA/B) grown at $30{ }^{\circ} \mathrm{C}\left(0^{\prime}\right)$ and heat shocked at $45^{\circ} \mathrm{C}$ for $15 \mathrm{~min}\left(15^{\prime}\right)$. Aliquots of the $\mathrm{S}, \mathrm{OM}$ and IM fractions, each containing $6 \mu \mathrm{g}$ protein and $24 \mu \mathrm{g}$ soluble (CP) proteins were subjected to $0.1 \%$ SDS- $15 \%$ PAGE and Western blotting with anti-IbpA/B serum. For determination of the IbpA/B level in each fraction (see text) it was taken into account that the insoluble proteins were loaded in 10-fold excess compared to the soluble CP fraction. Positions of $\mathrm{IbpA} / \mathrm{B}$ proteins are indicated by arrows. Soluble proteins constitute $87 \%$ of total cellular proteins, whilst the $S$ fraction contains $2 \%$ of the total protein.

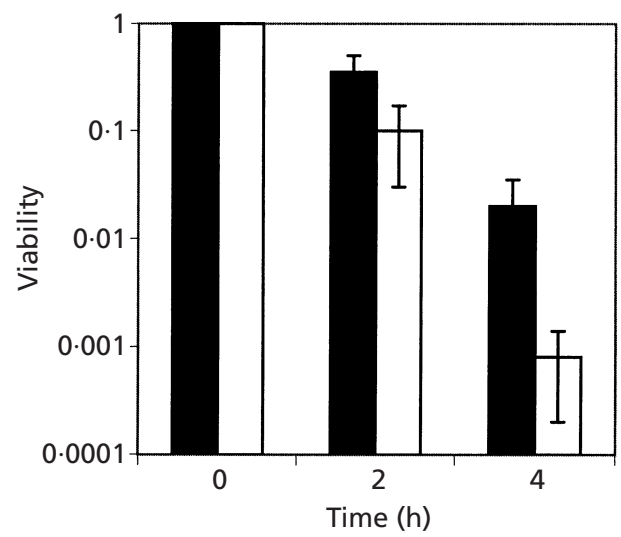

Fig. 4. Effect of the $\triangle i b p A / B$ mutation on viability of $E$. coli submitted to extreme heat shock at $50^{\circ} \mathrm{C}$. MC4100 (black bars) and MC4100 $\triangle$ ibpA/B bacteria (white bars) were grown in LB medium to a mid-exponential phase at $37{ }^{\circ} \mathrm{C}$ and transferred to $50{ }^{\circ} \mathrm{C}$. Serial dilution of cells were plated onto LB agar plates. The plates were incubated at $37^{\circ} \mathrm{C}$ for $18 \mathrm{~h}$ and colonies were counted. Error bars represent the standard deviation of three values.

localizing in the aggregate fraction. Similar results concerning localization of the $\mathrm{IbpA} / \mathrm{B}$ proteins were obtained when the cells were heat shocked at $50^{\circ} \mathrm{C}$ (not shown).

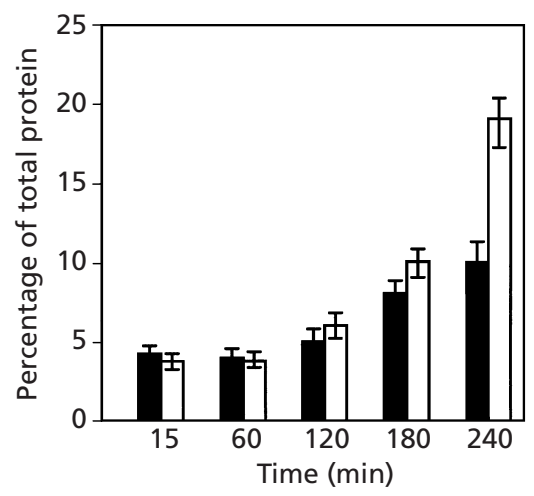

Fig. 5. Protein aggregation in $M C 4100$ and $M C 4100 \triangle i b p A / B$ cells (black and white bars, respectively) submitted to extreme heat shock $\left(50^{\circ} \mathrm{C}\right)$. The cells were grown at $37^{\circ} \mathrm{C}$ in LB medium to mid-exponential phase and transferred to $50{ }^{\circ} \mathrm{C}$. The $\mathrm{S}$ fraction was isolated from samples taken at the 15th min and the first, second, third and fourth hour after the temperature shift as described earlier (Fig. 1). The amount of aggregated proteins was calculated in relation to the total protein $(100 \%)$.

\section{IbpA/B participate in the removal of the $S$ fraction upon extreme heat shock}

We found that IbpA/B were dispensable for removal of the $S$ fraction proteins in cells exposed to heat stress at $45^{\circ} \mathrm{C}$ for $15 \mathrm{~min}$. The size of the $\mathrm{S}$ fraction formed at the 15 th min after the temperature shift to $45^{\circ} \mathrm{C}$ was about $10 \%$ smaller in the mutant than in the WT bacteria, but we did not observe any difference in the rate of $S$ fraction removal between the $\Delta i b p A / B$ mutant and WT cells (results not shown). Therefore, we exposed the $\Delta i b p A / B$ mutant to a more severe heat stress. We investigated the $S$-fraction formation and removal after the transfer of the WT and $\Delta i b p A / B$ cultures from $37^{\circ} \mathrm{C}$ to $50^{\circ} \mathrm{C}$, because we had found that at this temperature the $\Delta i b p A / B$ deletion substantially decreased viability of $E$. coli cells (Fig. 4). After $15 \mathrm{~min}$ and after $1 \mathrm{~h}$ following the temperature shift, about $4 \%$ of total protein was present in the $S$ fraction of both strains (Fig. 5). We observed again that slightly less protein was aggregated in the mutant cells than in the WT, similar to the case of cells submitted to heat shock at $45^{\circ} \mathrm{C}$. Prolonged exposure of the cultures to $50{ }^{\circ} \mathrm{C}$ revealed more noticeable differences. We observed that starting from the second hour after the temperature change, the level of aggregated proteins in the $\Delta i b p A / B$ strain increased faster and reached $18 \%$ of total protein at the fourth hour, whereas the $\mathrm{S}$ fraction in the WT contained only $10 \%$ of the total protein. These data indicate that $\mathrm{IbpA} / \mathrm{B}$ proteins participate in preventing aggregation of proteins after prolonged exposure to an extreme temperature. This result was consistent with the activity assay of fructose-1,6-bisphoshate aldolase (Fda) under extreme heat stress. Fda had previously been identified as one of the S-fraction proteins (Kędzierska et al., 2001). For this experiment E. coli(pKEN8) bacteria, overproducing Fda, were used, since the level of Fda in non-transformed cells was too low for reliable measure- 
(a)

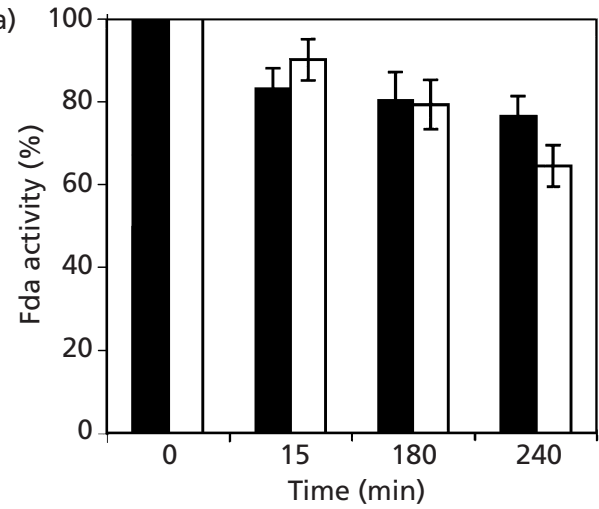

(b)

$\frac{0^{\prime}}{\text { WT } i b p} \frac{15^{\prime}}{\text { WT ibp }} \frac{180^{\prime}}{\text { WT ibp WT ibp }}$

$\mathrm{Fda}$

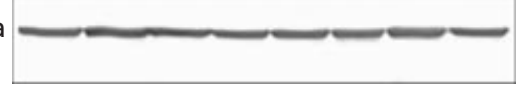

Fig. 6. Effect of $\triangle i b p A / B$ mutation on inactivation of $F d a$ in $E$. coli cells submitted to heat shock. MC4100 (black bars) and MC4100 $\triangle i b p A / B$ (white bars) transformed with pKEN8 were grown at $30{ }^{\circ} \mathrm{C}$ in LB medium. At an $\mathrm{OD}_{595}$ of 0.3 , IPTG was added to $1 \mathrm{mM}$. After $1 \mathrm{~h}$ growth, the bacteria were submitted to heat shock at $50^{\circ} \mathrm{C}$. (a) Fda activity was determined in cell lysates from samples collected at time 0 (before the temperature shift), after $15 \mathrm{~min}$, and 3 and $4 \mathrm{~h}$ at $50^{\circ} \mathrm{C}$. Error bars represent the standard deviation of three values. (b) The level of Fda was compared in cell extracts $(10 \mu \mathrm{g})$ submitted to $0.1 \%$ SDS- $12 \%$ PAGE and Western blotting with anti-Fda serum.

ments. It should be noted that the $\Delta i b p A / B$ mutation did not influence the level of the Fda in cells (Fig. 6b). Fifteen minutes after heat shock in the WT cells, the Fda activity decreased to $83 \%$ of its initial value, whereas in the $\triangle i b p A / B$ cells, $90 \%$ of the enzyme remained active (Fig. 6a). However, after a prolonged incubation $(4 \mathrm{~h})$ at $50{ }^{\circ} \mathrm{C}$, the activity of Fda decreased to $76 \%$ and to $64 \%$ in the WT and $\Delta i b p A / B$ cells, respectively. These data indicate that $\mathrm{IbpA} / \mathrm{B}$ protect $\mathrm{Fda}$ from inactivation upon extreme heat stress.

We also tested the capability of both strains to remove the $\mathrm{S}$ fraction during the recovery phase at $37^{\circ} \mathrm{C}$. When the cultures were heat shocked at $50{ }^{\circ} \mathrm{C}$ for $15 \mathrm{~min}$ and then transferred to $37^{\circ} \mathrm{C}$ for $20 \mathrm{~min}, 80 \%$ and $70 \%$ of aggregates were removed from $\Delta i b p A / B$ and WT cells, respectively (Fig. 7a). These results are in agreement with our previous notion that the elimination of $S$ fraction at $45^{\circ} \mathrm{C}$ is slightly more efficient in the absence of the IbpA/B proteins. However, this was not the case when the cultures were incubated at $50{ }^{\circ} \mathrm{C}$ for a longer period. Only $13 \%$ of the $S$ fraction formed within 4 h of incubation at $50^{\circ} \mathrm{C}$ was removed from $\triangle i b p A / B$ cells during $1 \mathrm{~h}$ at $37^{\circ} \mathrm{C}$ (Fig. $7 \mathrm{~b}$ ). Under the same conditions, WT cells coped more efficiently with the aggregates and $30 \%$ of the S-fraction proteins were removed. These data indicate that $\mathrm{IbpA}$ and $\mathrm{IbpB}$ are required for elimination of aggregates formed during long $(4 \mathrm{~h})$ exposure to $50^{\circ} \mathrm{C}$. (a) $50^{\circ} \mathrm{C}\left(15^{\prime}\right) \rightarrow 37^{\circ} \mathrm{C}\left(20^{\prime}\right)$

(b) $50^{\circ} \mathrm{C}(4 \mathrm{~h}) \rightarrow 37^{\circ} \mathrm{C}(1 \mathrm{~h})$
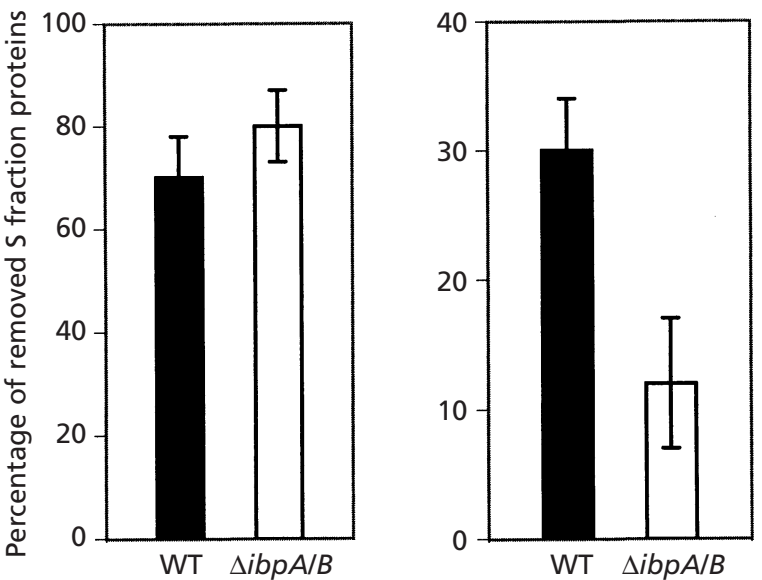

Fig. 7. Removal of the $S$ fraction from $E$. coli MC4100 (black bars) and MC4100 $\triangle i b p A / B$ (white bars) submitted to extreme heat shock. (a) The cells were grown at $37^{\circ} \mathrm{C}$ in LB medium to mid-exponential phase and transferred to $50^{\circ} \mathrm{C}$ for $15 \mathrm{~min}$. Thereafter the cultures were incubated at $37{ }^{\circ} \mathrm{C}$. The $\mathrm{S}$ fraction was isolated from samples taken $15 \mathrm{~min}$ after the temperature shift to $50^{\circ} \mathrm{C}$ and $20 \mathrm{~min}$ after subsequent growth at $37^{\circ} \mathrm{C}$ (at the 35th min of experiment). (b) The $\mathrm{S}$ fraction was isolated from cultures shocked at $50^{\circ} \mathrm{C}$ for $4 \mathrm{~h}$ and thereafter incubated at $37^{\circ} \mathrm{C}$ for $1 \mathrm{~h}$. Size of the $\mathrm{S}$ fraction isolated at $50^{\circ} \mathrm{C}$ was set to $100 \%$. Graphs present percentage of removed S fraction after recovery from heat shock. Error bars represent the standard deviation of three values.

To elucidate whether IbpA/B inhibit protein aggregation in general or protect some particular S-fraction proteins from aggregation upon extreme heat shock, we compared by two-dimensional electrophoresis the composition of the $S$ fractions isolated from the WT and $\triangle i b p A / B$ cells exposed to $50^{\circ} \mathrm{C}$ for $4 \mathrm{~h}$ and after $1 \mathrm{~h}$ recovery time at $37^{\circ} \mathrm{C}$ (Fig. 8). The overall pattern of the $\mathrm{S}$-fraction proteins seemed to be similar in all cases (compare Fig. 8a and b; c and d). One evident difference was a twofold higher level of DnaK in the $S$ fraction of $\Delta i b p A / B$ cells when compared to the WT aggregates (Fig. $8 \mathrm{a}, \mathrm{b}$ ). Taking into account that the same amount of protein was loaded on the two-dimensional gels and that the $S$ fraction of the $\Delta i b p A / B$ strain was almost twice as large as that of the WT strain (see Fig. 5, time point $240 \mathrm{~min}$ ), we estimate that after $4 \mathrm{~h}$ of heat shock the total amount of aggregated DnaK was approximately fourfold higher in the mutant than in the WT cells. It is interesting to note that under these conditions the levels of soluble DnaK in the mutant and WT cells were similar, though the total amount of DnaK was higher in mutant than in WT (Fig. 9). Two-dimensional PAGE analysis of the $S$ fraction isolated from cells stressed at $50{ }^{\circ} \mathrm{C}$ and subsequently incubated at $37^{\circ} \mathrm{C}$ revealed that all $\mathrm{S}$ fraction proteins were removed to a similar extent in both strains (Fig. 8c, d). Therefore, we assume that IbpA/B are responsible for inhibition of protein aggregation in general and participate in the removal of a whole spectrum of the S-fraction components rather than of particular proteins. 
(a)

(b)

$\mathrm{pH} 3.5$

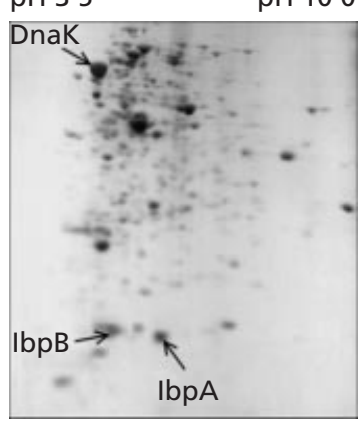

(c)

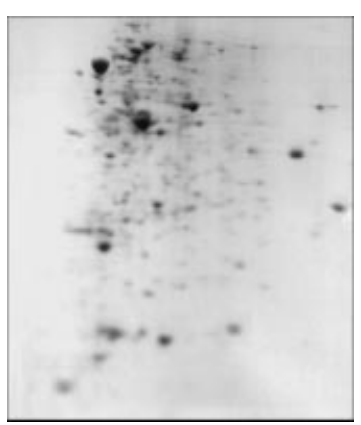

(d)

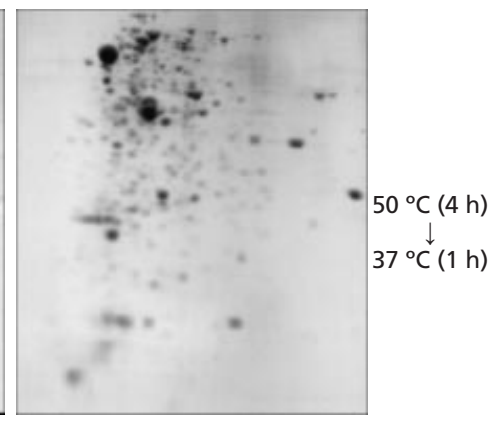

Fig. 8. Two-dimensional gel electrophoresis of the $S$ fraction proteins of $E$. coli MC4100 and MC4100 $\Delta i b p A / B$ isolated at $50{ }^{\circ} \mathrm{C}(4 \mathrm{~h})$ and after recovery time $(1 \mathrm{~h})$ at $37^{\circ} \mathrm{C}$. One hundred micrograms of proteins was loaded on each gel. DnaK, IbpA and $\mathrm{IbpB}$ were identified by Western blotting of identical gels (not shown). The presented gels were stained with Coomassie brilliant blue. Conditions of the experiment were as described in the legend to Fig. 5. Levels of DnaK were estimated by densitometry.

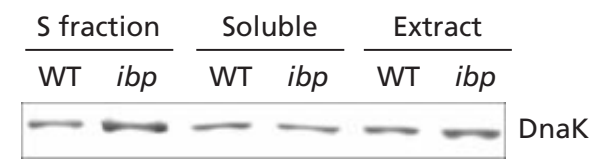

Fig. 9. Immunodetection of DnaK in the soluble fractions and aggregated proteins isolated from E. coli MC4100 and MC4100$\triangle i b p A / B$. Cells were heat shocked at $50{ }^{\circ} \mathrm{C}$ for $4 \mathrm{~h}$, as described in the legend to Fig. 5, and aliquots of the total cellular extracts, $\mathrm{S}$ and soluble (CP) fractions, containing $24 \mu \mathrm{g}, 6 \mu \mathrm{g}$ and $24 \mu \mathrm{g}$ protein, respectively, were subjected to $0.1 \%$ SDS$15 \%$ PAGE and immunoblotted with anti-DnaK serum.

\section{DISCUSSION}

According to the current model, based on in vitro studies, the function of ATP-independent sHsps is crucial under the depletion of ATP level caused by heat stress. sHsps hold non-native proteins, preventing them from irreversible aggregation until conditions permissive for refolding by ATP-dependent DnaK/DnaJ and GroEL/GroES are restored (Ehrnsperger et al., 1997; Veinger et al., 1998; Lee \& Vierling, 2000). In this work we investigated the function of IbpA and IbpB proteins in vivo, analysing the formation and removal of denatured and aggregated proteins ( $\mathrm{S}$ fraction) in E. coli. We showed that the overproduction of IbpA, IbpB or both sHsps resulted in stabilization of the $S$ fraction after heat shock (Fig. 1b). Thus, overproduction of sHsps causes the opposite effect to that observed in cells with excess ATP-dependent chaperones (DnaK/DnaJ, GroEL/GroES systems) which prevent S-fraction formation (Kędzierska et al., 1999). These in vivo data are in agreement with the model described above. From the analysis of protein content of the $S$ fraction (Fig. 1a) formed at $45^{\circ} \mathrm{C}(15 \mathrm{~min})$, we concluded that IbpA and IbpB may exhibit different affinities for unfolded proteins. The precursor of periplasmic $\beta$-lactamase is an example of unfolded protein, which in vivo accompanied IbpA but not IbpB in the fraction of protein aggregates. Translocation of the $\beta$-lactamase precursor to the periplasmic space requires GroEL/GroES chaperone machinery. It is also suggested that DnaK/DnaJ and SecB may cooperate with GroEL/ES in this transport (Laminet et al., 1990; Wild et al., 1996). In general, chaperones prevent complete folding of precursor proteins in the cytoplasm and hold them in a loose, 'translocation-competent' conformation prerequisite for the transport of proteins across membranes. It seems that stable interaction of IbpA with partly unfolded $\beta$ lactamase precursor inhibits its chaperone-assisted translocation to the periplasm since the growth of E. coli cells overproducing IbpA, in the medium supplemented with ampicillin, required an increased level of the precursor (Fig. 2).

When IbpA and IbpB were produced together, both sHsps were present in fractions of aggregated proteins and absent in the soluble protein fraction. It is interesting that in the absence of IbpA, most of the IbpB remained in a soluble fraction and only $2 \%$ of total IbpB colocalized with the aggregated proteins (Fig. 3). The observed influence of IbpA on localization of $\mathrm{IbpB}$ suggests that mixed IbpA-IbpB complexes may be formed. The formation of such complexes has been described by Studer \& Narberhaus (2000).

It is remarkable that after a temperature change from $30{ }^{\circ} \mathrm{C}$ to $42{ }^{\circ} \mathrm{C}$ the cellular level of IbpA/B increases almost 10-fold, whereas the amount of DnaK and GroEL is only twofold higher (Mogk et al., 1999). This indicates that IbpA/B are particularly important at high temperatures compared to other chaperones that function also under physiological conditions. However, we demonstrated that when E. coli cells were exposed to high temperatures for a relatively short period (15 min at $45^{\circ} \mathrm{C}$ ), protein aggregates could be eliminated by chaperones without the participation of sHsps. Moreover, we showed here that heat inactivation of Fda, one of the S-fraction proteins, was less efficient in E. coli cells lacking IbpA/B. Recently, it was found that DnaK/ DnaJ, but not GroEL/GroES, were essential for the reactivation of heat-denatured Fda in vivo (Kędzierska et al., 2001). Taken together, these data suggest that in the WT cells IbpA/B proteins may slightly inhibit the Fda refolding by DnaK/DnaJ, probably by blocking the 
DnaK/DnaJ-binding sites in denatured proteins. A similar effect was reported in vitro: the rate of refolding of thermolabile malate dehydrogenase and lactate dehydrogenase denatured in the presence of DnaK/J and incubated with GroEL/ES after heat shock was higher than that of the enzymes bound to IbpB during denaturation and incubated subsequently with the DnaK/J-GroEL/ES systems (Veinger et al., 1998). We demonstrated that IbpA/B were required for the suppression of protein aggregation and for the elimination of the $S$ fraction formed during extended $(2-4 \mathrm{~h}$ ) treatment at $50{ }^{\circ} \mathrm{C}$ (Figs 6 and 7). Analysis of the protein content of the $\mathrm{S}$ fraction indicated that upon extreme heat stress IbpA/B did not protect any particular proteins from aggregation but suppressed protein aggregation in general (Fig. 8a, b). Removal of proteins from the $S$ fraction was not specific either (Fig. 8c, d). However, we found that after prolonged exposure to $50{ }^{\circ} \mathrm{C}$ the mutant $\Delta i b p A / B$ strain contained a higher amount of DnaK than the WT strain and this excess was localized in the $S$ fraction (Figs 8 and 9). The increased amount of DnaK in the fraction of aggregated proteins might be a direct consequence of the lack of the IbpA/B : hydrophobic segments of unfolded proteins, usually recognized and bound by $\mathrm{IbpA} / \mathrm{B}$, would become available for DnaK. Increased binding of DnaK by the unfolded proteins would in turn cause a decrease in the level of soluble DnaK, which, according to the model of regulation of heat-shock response (Tomoyasu et al., 1998), would result in higher activity of $\sigma^{32}$ and intensified production of DnaK. Such an overall increase in the DnaK level is indeed observed in the mutant cells (Fig. 9).

The damage caused by heat treatment at $50{ }^{\circ} \mathrm{C}$ comprises degradation of ribosomes and inactivation of macromolecular synthesis (Neidhardt \& VanBogelen, 1987); thus, after long exposure to $50{ }^{\circ} \mathrm{C}$, when the function of IbpA/B becomes important for cell survival, the level of IbpA/B cannot be increased. Therefore, IbpA/B may have to be strongly induced immediately after a temperature upshift, even though their function is dispensable in the case of relatively short-term heat stress. This may thus provide an explanation for the apparently paradoxical result that the IbpA/B proteins are very strongly induced on heat shock but that $\triangle i b p A B$ strains show no significant phenotype at normal heatshock temperatures.

\section{ACKNOWLEDGEMENTS}

This work was supported by grants from the Polish Committee for Scientific Research (KBN 0461/P04/2001/20, KBN 0345/ P04/99/16), University of Gdańsk (BW/1160-5-0075-1) and from the Royal Society [NATO/98B/nvb (for E.L.)].

\section{REFERENCES}

Allen, S. P., Polazzi, J. O., Gierse, J. K. \& Easton, A. M. (1992). Two novel heat shock genes encoding proteins produced in response to heterologous protein expression in E. coli. J Bacteriol 174, 6938-6947.

Bradford, M. M. (1976). A rapid and sensitive method for quantition of protein utilizing the principle of protein-dye binding. Anal Biochem 72, 248-254.

Cobb, B. A. \& Petrash, J. M. (2000). Characterization of alphacrystallin-plasma membrane binding. J Biol Chem 275, 66646672.

Ehrnsperger, M., Gräber, S., Gaestel, M. \& Buchner, J. (1997). Binding of non-native protein to Hsp25 during heat shock creates a reservoir of folding intermediates for reactivation. EMBO J 16, 221-229.

Jacob, U. \& Buchner, J. (1994). Assisting spontaneity: the role of Hsp90 and small Hsp as molecular chaperones. Trends Biochem Sci 19, 205-211.

Kȩdzierska, S., Staniszewska, M., Wȩgrzyn, A. \& Taylor, A. (1999). The role of DnaK/DnaJ and GroEL/GroES systems in the removal of endogenous proteins aggregated by heat-shock from Escherichia coli cells. FEBS Lett 446, 331-337.

Kędzierska, S., Jezierski, G. \& Taylor, A. (2001). DnaK/DnaJ chaperone system reactivates endogenous E. coli thermostable FBP aldolase in vivo and in vitro; the effect is enhanced by GroE heat shock proteins. Cell Stress Chaperones 6, 29-37.

Kitagawa, M., Matsumura, Y. \& Tsuchido, T. (2000). Small heat shock proteins, IbpA and IbpB, are involved in resistances to heat and superoxide stresses in E. coli. FEMS Microbiol Lett 184, 165-171.

Kucharczyk, K., Laskowska, E. \& Taylor, A. (1991). Response of $E$. coli cell membranes to induction of $\lambda \mathrm{cI} 857$ prophage by heat shock. Mol Microbiol 5, 2935-2945.

Laemmli, U. K. (1970). Cleavage of structural proteins during the assembly of the head of bacteriophage T4. Nature 227, 680-685.

Laminet, A. A., Ziegelhoffer, T., Georgopoulos, C. \& Pluckthun, A. (1990). The Escherichia coli heat shock proteins GroEL and GroES modulate the folding of the beta-lactamase precursor. EMBO J 9, 2315-2319.

Laskowska, E., Wawrzynów, A. \& Taylor, A. (1996a). IbpA and $\mathrm{IbpB}$, the new heat-shock proteins, bind to endogenous Escherichia coli proteins aggregated intracellularly by heat shock. Biochimie 78, 117-122.

Laskowska, E., Kuczyńska-Wiśnik, D., Skórko-Glonek, J. \& Taylor, A. (1996b). Degradation by proteases Lon, Clp and HtrA of Escherichia coli proteins aggregated in vivo by heat shock; HtrA protease action in vivo and in vitro. Mol Microbiol 22, 555-571.

Lee, G. J. \& Vierling, E. (2000). A small heat shock protein cooperates with heat shock protein 70 system to reactivate a heatdenatured protein. Plant Physiol 122, 189-197.

Liu, C. \& Welsh, M. J. (1999). Identification of a site of Hsp27 binding with Hsp27 and $\alpha \mathrm{B}$-crystallin as indicated by the yeast two-hybrid system. Biochem Biophys Res Commun 255, 256-261.

MacRea, T. H. (2000). Structure and function of small heat shock $\alpha$ crystalline proteins: established concept and emerging ideas. CMLS Cell Mol Life Sci 57, 899-913.

Meerman, H. J. \& Georgiou, G. (1994). Construction and characterization of a set of $E$. coli strains deficient in all known loci affecting the proteolytic stability of secreted recombinant proteins. Bio/Technology 12, 1107-1110.

Mogk, A., Tomoyasu, T., Goloubinoff, P., Rüdiger, S., Röder, D., Langen, H. \& Bukau, B. (1999). Identification of thermolabile E. coli proteins: prevention and reversion of aggregation by DnaK and ClpB. EMBO J 24, 6934-6949.

Neidhardt, F. C. \& VanBogelen, R. A. (1987). Heat shock response. In Escherichia coli and Salmonella typhimurium: Cellular and Molecular Biology, pp. 1334-1345. Edited by F. C. Neidhardt and others. Washington, DC: American Society for Microbiology. 
Rajaraman, K., Raman, B., Ramakrishna, T. \& Mohan Rao, Ch. (2001). Interaction of human recombinant $\alpha \mathrm{A}$ - and $\alpha \mathrm{B}$-crystallins with early and late unfolding intermediates of citrate synthase on its thermal denaturation. FEBS Lett 497, 118-123.

Shearstone, J. R. \& Baneyx, F. (1998). Biochemical characterization of the small heat shock protein IbpB from Escherichia coli. J Biol Chem 274, 9937-9945.

Studer, S. \& Narberhaus, F. (2000). Chaperone activity and homoand hetero-oligomer formation of bacterial small heat shock proteins. J Biol Chem 275, 37212-37218.

Thomas, J. G. \& Baneyx, F. (1998). Roles of the E. coli small heat shock proteins IbpA and IbpB in thermal stress management: comparison with ClpA, ClpB and HtpG in vivo. J Bacteriol 180, 5165-5172.

Tomoyasu, T., Ogura, T., Tatsuta, T. \& Bukau, B. (1998). Levels of DnaK and DnaJ provide tight control of heat shock gene expression and protein repair in E. coli. Mol Micobiol 30, 567-581.

Veinger, L., Diamant, S., Buchner, J. \& Goloubinoff, P. (1998). The small heat-shock protein IbpB from E. coli stabilizes stressdenatured proteins for subsequent refolding by a multichaperone network. J Biol Chem 273, 11032-11037.

Wild, J., Rossmeissl, P., Walter, W. A. \& Gross, C. A. (1996). Involvement of the DnaK-DnaJ-GrpE chaperone team in protein secretion in Escherichia coli. J Bacteriol 178, 3608-3613.

Wilson, K. J. \& Juan, P. M. (1989). Protein and peptide purification. In Protein Sequencing: a Practical Approach, pp. 1-41. Edited by J. B. C. Findlay \& M. J. Geisow. Oxford: Oxford University Press.

Received 26 October 2001; revised 25 February 2002; accepted 28 February 2002. 